FACULdADE DE CIÊNCIAS ECONÔ MICAS DA UFRGS

MACROECONOMIA DO BRASIL PÓS-1994 LUIZ CARLOS BRESSER-PEREIRA

DESENVOLVIMENTO ECONOMMICO, PREFERÊNCIA PELA LIQUIDEZ E ACESSO BANCÁRIO: UM ESTUDO DE CASO DAS MESORREGIÓES DE MINAS GERAIS

MARCO CROCCO, CLAUDIO BARRA DE CASTRO, ANDERSON CAVALCANTE E VANESSA DA COSTA VAL

FRIEDMAN E O MONETARISMO: A VELHA TEORIA QUANTITATIVA DA MOEDA E A MODERNA ESCOLA MONETARISTA

GENTIL CORAZZAE RODRIGO L. KREMER

BOLLHAS RACIONAIS, CICLO DE PREÇOS DE ATIVOS E RACIONALIDADE LIMITADA: UMA AVALIACAOO CRITICA DOS MODELOS NEOCLÁSSICOS DE BOLHAS ESPECULATIVAS JOSÉ LUIS OREIRO

VULNERABILITY INDICATORS OF THE TWIN CRISES: THE EAST ASIAN EPISODE

TITO BELCHIOR SILVA MOREIRA

IMPACTOS POTENCIAIS DA NEGOCIAÇÃO DA ALCA SOBRE OS INVESTIMENTOS EXTERNOS EM SERVIÇOS PROFISSIONAIS NO BRASIL

MICHEL ALEXANDRE, OTAVIANO CANUTO E GILBERTO TADEU LIMA

TEORIA MARXISTA DO VALOR: UMA INTRODUÇẢO ALFREDO SAAD FILHO

UM ESTUDO EMPIRICO DOS CICLOS POLITICO. ECONOOMICOS NO BRASIL

ATHOS PRATES DA SILVEIRA PREUSSLER E MARCELO SAVINO PORTUGAL

RELENDO CHANDLER, WILLIAMSON E NORTH PARA ENTENDER O PROCESSO DE FORMACĀO DAS ESTRADAS DE FERRO NO BRASIL

JEFFERSON ANDRONIO RAMUNDO STADUTO

WEIMAR FREIRE DA ROCHA IR. E CLAIITON ATAIDES DE FREITAS

MATRIZ DE INSUMO-PRODUTO PARA A ECONOMIA TURISTICA BRASILEIRA: CONSTRUCCÃO E ANÁLISE DAS RELAÇÓES INTERSETORIAIS

FRANCISCO CASIMIRO FILHO E JOAQUIM JOSÉ MARTINS GUILHOTO

SEÇĀO ESPECIAL: AVALIAÇŌES INICIAIS DA POLITTICA ECONÓMICA DO GOVERNO LULA

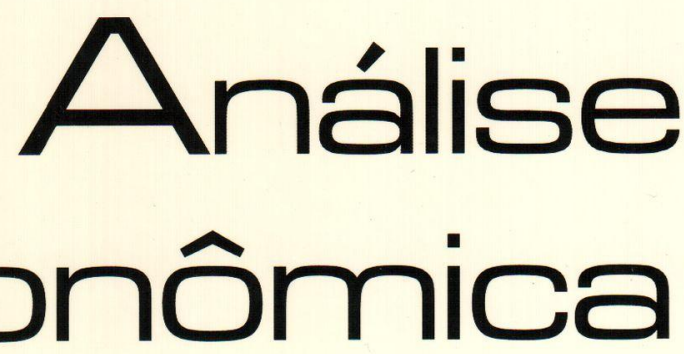


Universidade Federal do Rio Grande do Sul

Reitora: Profa. Wrana Maria Panizzi

Faculdade de Ciencias EConómicas

Diretora: Prof Pedro César Dutra Fonseca

Centro de Estudos e Pesquisas Economicas

Diretor: Prof. Gentil Corazza

Departamento de Ciéncias económicas

Chiefe: Prof. Ricardo Dathein

Curso de Pós. Graduação em Economia

Coordenador: Prof. Eduardo Pontual Ribeiro

Programa de Pós-Graduação em Desenvolvimento Rural

Coordenador: Prof. jalcione Almeida

CONSElHo EDITORIAL:

Carlos G. A. Mielitz Netto (UFRGS), Eduardo A. Maldonado Filho (UFRGS), Eduardo P. Ribeiro (UFRGS), Eleutério F. S. Prado (USP), Eugênio Lagemann (UFRGS), Fernando Cardim de Carvalho (UFRJ), Fernando Ferrari Filho (UFRGS), Fernando de Holanda Barbosa (FGV/RJ), Flávio Vasconcellos Comim (UFRGS), Gentil Corazza (UFRGS), Giácomo Balbinotto Netto (UFRGS), Gustavo Franco (PUC/RJ), Jan A. Kregel (UNCTAD), João Rogério Sanson (UFSC), Joaquim Pinto de Andrade (UnB), Jorge Paulo Araújo (UFRGS), Marcelo S. Portugal (UFRGS), Maria Alice Lahorgue (UFRGS), Paul Davidson (University of Tennessee), Paulo D. Waquil (UFRGS), Pedro C. D. Fonseca (UFRGS), Philip Arestis (Levy Economics Institut of Bard College), Roberto C. de Moraes (UFRGS), Ronald Otto Hillbrecht (UFRGS), Sabino da Silva Porto Jr. (UFRGS), Stefano Florissi (UFRGS) e Werner Baer (University of Illinois at UrbanaChampaign).

COMISSÃO EDITORIAL:

Eduardo Augusto Maldonado Filho, Fernando Ferrari Filho, Gentil Corazza, Marcelo Savino Portugal, Paulo Dabdab Waquil e Roberto Camps Moraes.

EDIroR: Prof. Fernando Ferrari Filho

Editor Adunnio: Prof. Gentil Corazza

SECRETÁrla: Clarissa Roncato Baldim

REVISÁO DE TEXTOS: Vanete Ricacheski

EDITORaÇão Eletrónica: Vanessa Hoffmann de Quadros

Fundador: Prof Antônio Carlos Santos Rosa

Os materiais publicados na revista Análise Econômica são da exclusiva responsabilidade dos autores. É permitida a reprodução total ou parcial dos trabalhos, desde que seja citada a fonte. Aceita-se permuta com revistas congêneres. Aceitam-se, também, livros para divulgação, elaboraçāo de resenhas e recensōes Toda correspondência, material para publicaçāo (vide normas na terceira capa), assinaturas e permutas devem ser dirigidos ao seguinte destinatário:

Análise Econômico

PROF FERNANDO FERRARI FILHO Revisła Análise Econômica - Av. João Pessoa, 52 CEP 90040-000 PORTO ALEGRE - RS, BRASL Telefones: (051) 316-3513 - Fax: (051) 316-3990 E-mail: rae@ufrgs.br

Ano 21, $n^{\circ} 39$, março, 2003 - Porto Alegre

Faculdade de Ciências Econômicas, UFRGS, 2003

Periodicidade semestral, março e setembro.

Tiragem: 500 exemplares

1. Teoria Econômica - Desenvolvimento Regional.

Economia Agrícola - Pesquisa Teórica e Aplicada -

Periódicos. I. Brasil

Faculdade de Ciências Econômicas,

Universidade Federal do Rio Grande do Sul 


\title{
Friedman e o monetarismo: A Velha Teoria Quantitativa da Moeda e a Moderna Escola Monetarista
}

\author{
Gentil Corazza \\ Rodrigo L. Kremer ${ }^{2}$ \\ "O que precisamos não é um hábil condutor monetário do veículo \\ econômico tentando compensar, com golpes de direção, as \\ irregularidades imprevistas da estrada, mas uma forma de evitar \\ que o passageiro monetário, que se senta no banco traseiro como \\ um lastro, se incline para frente e se agarre ao volante, \\ ameaçando lançar o carro para fora da estrada".
}

Milton Friedman

\begin{abstract}
The paper aims to present the evolution of the Quantitative Theory of Money from its initial formulation to Friedman's final proposal. It aims also to analyze the principles of Economic Policy resulting from this reinterpretation of Quantitative Theory elaborated by Friedman and other monetarist economists.
\end{abstract}

Key Words: Monetarism. Quantitative Theory of Money, Friedman

JEL Classification: $6.03 .03 .01-8$

\section{Introdução}

Milton Friedman, destacado economista norte-americano, é considerado na história do pensamento econômico como sendo o. fundador e principal expoente da Escola Monetarista. As raízes do monetarismo estão na Teoria Quantitativa da Moeda, que é o esqueleto teórico da Economia Monetária do século XVIII. Os economistas vinculados a esta escola de pensamento que tem como figuras eminentes, além do próprio Friedman, nomes como os de Karl Brunner, Allan Meltzer e Philip Cagan nos Estados Unidos e David Laidler na Grã-Bretanha, advogam os princípios de política econômica oriundos da moderna interpretação da Teoria Quantitativa da Moeda propostos por Friedman na coletânea de artigos Studies in

\footnotetext{
1 Professor adjunto do departamento de Economia da UFRGS.

${ }^{2}$ Aluno do curso de mestrado do Programa de Pós-Graduação em Economia da UFRGS. Bolsista do CNPQ.

- Os autores agradecem os comentários do parecerista da Revista Análise Econômica.
} 
the Quantity Theory of Money (1956). O desenrolar deste corpo teórico acabou por propor regras de crescimento constante da oferta monetária em detrimento de medidas discricionárias de política monetária, como sendo a forma mais eficiente de as autoridades monetárias promoverem a estabilidade do nível de preços e o crescimento sustentado do produto per capita.

A Escola de Chicago sempre se caracterizou por enfatizar a importância do controle da oferta monetária. Antes de Friedman, Henry Simons, em 1936, já defendia o controle da oferta monetária como forma de estabilizar o nível de preços, e Lloyd Mints, em 1950, estabelecia um programa monetário específico para estabilizar os índices de preços.

Mas o receituário monetarista não estava restrito à Escola de Chicago. James Angel, da Universidade de Columbia, já em 1933, defendia um crescimento constante da oferta monetária, e, no pósSegunda Guerra, Karl Brunner e Allan Meltzer foram influentes divulgadores do Monetarismo. Brunner $\& 3$ Meltzer fundaram, nos anos 1970, o Shadow Open Market Comittee para divulgar o ideário monetarista de como o FED (Banco Central dos Estados Unidos) deveria conduzir a política monetária.

O período de ouro do Monetarismo deu-se na década de 1970. Tanto em termos acadêmicos quanto em nível de medidas de política econômica, estes anos representaram o apogeu desta escola. Nesta época, não ser monetarista representava estar à margem do mainstream do pensamento econômico. Os economistas advindos da Universidade de Chicago, fortemente identificados com o ideário monetarista, aplicaram seu receituário em vários países, dentre os quais os casos do Chile e da Bolívia ilustram bem a experiência monetarista na gestão de política econômica na América Latina. Alguns analistas consideram que a gestão Volcker à frente do FED foi fortemente influenciada pelo receituário monetarista.

A perspectiva monetarista tem tido grande influência ao longo dos últimos tempos. De Outubro de 1979 ao Outono de 1982, teve lugar nos Estados Unidos uma experiência monetarista em escala ampliada. A Reserva Federal deixou de influenciar as taxas de juros no sentido da baixa e concentrou-se totalmente na manutenção do crescimento monetário, de acordo com determinados parâmetros (Samuelson E Nordhaus, 1988, pg. 403).

Com a revolução dos economistas novos-clássicos e a ascensão da Teoria das Expectativas Racionais, progressivamente o 
Monetarismo foi perdendo importância dentro da Macroeconomia contemporânea ${ }^{3}$.

O primeiro estudo empírico a dar suporte à interpretação monetarista da causa dos ciclos econômicos reais foi a série de estudos, baseados em dados da economia norte-americana, promovido por Clark Warburton, em 1946. Posteriormente, Friedman 8 Anna Schwartz compilaram novos dados do National Bureau of Economic Research em prosseguimento aos estudos de Warburton. Em 1962, os referidos autores demonstraram que flutuações no crescimento da oferta monetária precederam tanto picos quanto vales nos ciclos de negócios da economia dos Estados Unidos desde a Guerra Civil daquele país no século XIX.

O objetivo deste trabalho é apresentar a evolução da Teoria Quantitativa da Moeda desde sua versão inicial ${ }^{4}$ até sua forma final proposta por Friedman, bem como, analisar os princípios de política econômica oriundos desta reinterpretação da Teoria Quantitativa efetuada pelo referido autor e pelos demais economistas monetaristas.

\section{A Teoria Quantitativa da Moeda e seus Postulados Básicos}

Essencialmente, a Teoria Quantitativa da Moeda é a hipótese sobre a causa principal das variaçóes no valor da moeda. Estabelece que o estoque de moeda, " $\mathrm{M}$ ", é o principal determinante do nível geral de preços, "P". Os economistas clássicos/neoclássicos ${ }^{5}$ chegaram a esta conclusão, a partir da hipótese de que o produto real a

\footnotetext{
${ }^{3}$ Em parte, esta perda de importância deu-se pelas experiências de política econômica implementadas com pouco êxito, em vários paises na década de 1970, embasadas no ideário monetarista. Além disto, economistas novos-clássicos, como Robert Lucas Jr., Robert Barro, Thomas Sargent, Edward Prescott, Robert Townsend e Neil Wallace, ao definirem seu modelo de expectativas como racionais, não concordavam que, mesmo no curto prazo, a política monetária pudesse ter um impacto positivo sobre o nivel de renda real da economia. Deste modo, tais autores consideram a curva de oferta agregada como sendo vertical, inclusive no curto prazo, contrariando a concepção monetarista de existência de trade-off, ainda que temporário, entre crescimento e inflação.

${ }^{4}$ Como o objetivo principal deste trabalho é analisar a reinterpretação da Teoria Quantitativa da Moeda proposta por Friedman, como também as implicações de política econômica advindas da mesma, não será aqui analisada a contribuição desenvolvida por Knut Wicksell à Teoria Quantitativa da Moeda. Uma boa exposição sobre a abordagem wickselliana é encontrada em Simonsen (1983, cap. 1).

${ }^{5}$ Ao utilizar-se a expressão economistas clássicos, está-se fazendo referência a Smith, Ricardo e Mill. Já a expressão economistas neoclássicos refere-se a Marshall, Fisher e Pigou.
} 
preços constantes de qualquer economia depende exclusivamente de variáveis reais (fatores de produção e função de produção agregada) e que a velocidade de circulação da moeda varia de forma lenta e previsível a longo prazo (dependendo de fatores como o grau de desenvolvimento do setor bancário, freqüência de pagamentos e recebimentos, rapidez de transporte e comunicações), podendo ser considerada uma constante no curto prazo. A conclusão de que o produto real a preços constantes depende somente de fatores reais é obtida a partir da hipótese de flexibilidade de preços, tanto no mercado de bens e serviços quanto no mercado de trabalho, tornando-se conhecida na literatura como "equilibrio clássico de pleno emprego" (Ackley 1978, cap. VI). Como afirma Garegnani: "We have seen that the 'Classical' proposition criticised by Keynes concerned the existence of forces leading to the full employment of labour" (Garegnani (1978, p. 341).

Uma descrição precisa e detalhada desta questão é encontrada em Swaelen (1982), especialmente capítulo 3, seção 3.2.

A primeira versão da Teoria Quantitativa da Moeda apareceu na literatura econômica como Equação Quantitativa na forma de transações, sendo formulada por Simon Newcomb, em 1885 (Spiegel, 1992, p. 617) mas quem popularizou esta versão foi Irving Fisher, em 1911, em The Purchasing Power of Money (Friedman, 1990 , p. 04). Porém, a noção de que a oferta monetária afeta o nível geral de preços se fazia presente há alguns séculos na história do pensamento econômico. Já no século XVI, Jean Bodin argumentava a M. de Malestroit (Simonsen 1983, p. 21) que o aumento no nível geral de preços que então se observava na França não se explicava somente pela aversão ao padrão metálico da unidade monetária, mas principalmente pela maior disponibilidade de ouro no país. David Hume em seu ensaio Of Money, de 1752, foi o primeiro pensador a analisar de modo mais rigoroso a relação entre variáveis monetárias e variáveis reais.

O ponto de partida para se obter a Equação Quantitativa é observar a identidade existente entre o total de pagamentos em moeda e o total de bens e serviços transacionados. Note-se que, em cada ato de compra e venda de um bem ou serviço qualquer, os pagamentos em moeda e o valor monetário dos bens e serviços trocados são iguais. Logo, o total de moeda paga nas transações é igual ao valor monetário total dos bens e serviços comprados. Então, tem-se que:

$\mathrm{MV}=\mathrm{PT}$ 
onde:

$\mathrm{M}$ = estoque monetário/ oferta monetária;

$\mathrm{V}$ = velocidade de circulação da moeda;

$\mathrm{P}$ = nível geral de preços;

$\mathrm{T}$ = quantidade total de transações físicas de bens e serviços;

$\mathrm{PT}=$ total das transferências de bens e serviços entre os agentes econômicos;

$\mathrm{MV}=$ total das transferências de moeda entre os agentes para pagamento dos bens comprados.

ou ainda,

$\mathrm{MV}+\mathrm{M}^{\prime} \mathrm{V}^{\prime}=\mathrm{PT}$

onde:

$\mathrm{M}$ = total do papel moeda em poder do público;

$\mathrm{M}^{\prime}$ = total dos depósitos à vista do público nos bancos comerciais; público;

$\mathrm{V}$ = velocidade de circulação do papel moeda em poder do

$\mathrm{V}^{\prime}$ = velocidade de circulação dos depósitos à vista do público nos bancos comerciais;

$\mathrm{P}=$ nível geral de preços;

$\mathrm{T}$ = quantidade total de transações físicas de bens e serviços;

$\mathrm{PT}=$ total das transferências de bens e serviços entre os agentes econômicos.

A vantagem em utilizar a equação ( 2 ), em relação à equação ( 1 ), é a maior facilidade de calcular V' via dados dos bancos comerciais, ao invés de calcular $V$ na equação ( 1 ). É importante notar que na equação ( 1 ) "M" é uma variável de estoque, enquanto o produto "PT" corresponde a uma variável de fluxo.

James Angel, da Universidade de Columbia, em 1936, desenvolveu a forma renda da Teoria Quantitativa da Moeda. Tal forma consiste basicamente em expressar a Equação Quantitativa em termos da renda nominal ao invés das transações. Sabe-se das Contas Nacionais que:

$\mathrm{Y}=\mathrm{PNy}=\mathrm{Py}^{\prime}$

onde:

$\mathrm{Y}=$ renda nominal;

$\mathrm{N}=$ número de habitantes de certo país;

$\mathrm{P}=$ nível geral de preços;

$\mathrm{y}=$ renda per capita a preços constantes;

$\mathrm{y}^{\prime}=$ renda nacional a preços constantes;

Logo $\mathrm{MV}=\mathrm{PT}$ 
$\mathrm{De}(3) \mathrm{em}$ ( 1 )

$\mathrm{MV}=\mathrm{PNy}=\mathrm{Py}^{\prime}$

$\operatorname{De}(2)$ em (4)

$\mathrm{MV}+\mathrm{M}^{\prime} \mathrm{V}^{\prime}=\mathrm{PNy}=\mathrm{Py}^{\prime}$

A Equação Quantitativa na forma de transações, ( 1 ), apresenta "V" como a velocidade de circulação da moeda. Assim, "V" é por vezes definida como a taxa à qual a moeda circula dentro da economia. Ela pode ser obtida pelo quociente entre o total das transferências de bens e serviços entre os agentes econômicos, "PT", e a oferta monetária, "M", logo: $\mathrm{V}=\mathrm{PT} / \mathrm{M}$.

Já a Equação Quantitativa na forma renda, (4), "V" é denominada velocidade renda da moeda e representa o número de vezes que uma nota de unidade monetária entra na renda de um agente econômico em um dado período. Assim, pode-se obter a velocidade renda da moeda como o quociente entre a renda nominal, "Py' ", e a oferta monetária, "M".

Contudo, como os economistas clássicos não fazem distinção entre curto e longo prazo, isto é, preços e salários são flexíveis tanto no curto quanto no longo prazo e a lei de Say sempre se verifica, então o produto per capita está sempre em seu nível de pleno emprego. Como os economistas clássicos supõem ser a velocidade de circulação da moeda constante a curto prazo, daí surge que alterações no nível geral de preços, "P", ocorrem devido às mudanças na oferta monetária, "M". Em suma, a Teoria Quantitativa da Moeda diz que, como "V" e "y"' são constantes, um aumento na oferta monetária faz com que o nível geral de preços aumente exatamente na mesma proporção do aumento verificado na mesma. Este é o embasamento teórico da dicotomia clássica: variáveis reais não são afetadas por variáveis monetárias. Logo, um aumento na oferta monetária não afeta o produto real per capita nem mesmo no curto prazo, pois preços e salários são flexíveis a curto prazo (isto é, aumentos de demanda agregada oriundos do aumento na oferta monetária somente aumentam o nível geral de preços, pois a economia sempre opera a pleno emprego). Humphrey faz uma interessante colocação a este respeito, ao afirmar que:

Enquanto a análise de Cantillon-Hume enfatizou os efeitos da inflação sobre o produto e o emprego, analistas clássicos virtualmente os ignoraram, ou trataram como insignificantes esses efeitos reais. Na visão hegemônica, a posição dos mais influentes entre os economistas clássicos, especialmente David Ricardo, era que estes efeitos desequilibradores eram efêmeros e 
desimportantes, meras qualificações da análise de equilíbrio de longo prazo. Esta opiniāo pode ter sido condicionada pela propensão de Ricardo para a abstração via teoria estático-comparativa. Ou talvez, revela seu desejo de uma teoria descomplicada e convincente para suportar sua avaliação que a inflaçāo na Grã-Bretanha era somente o resultado da irresponsabilidade do Banco da Inglaterra, sobre-emitindo meio circulante (Humphrey 1992, p. 38-9).

A moeda, ao separar o ato de compra do ato de venda, faz com que os agentes econômicos mantenham seu poder de compra via retenção da mesma. Os economistas neoclássicos deram uma nova interpretaçāo à Teoria Quantitativa da Moeda, na versão dos saldos monetários (cash-balance) de Cambridge. Na ótica dos saldos monetários, a moeda serve como uma "moradia temporária" para o poder de compra geral, no intervalo de tempo entre a venda e a compra de um bem ou serviço qualquer. Assim, fica claro que a moeda tem a propriedade de transportar poder de compra do presente para uma data futura qualquer. É importante ter em mente que o ponto em que os economistas neoclássicos focam sua análise é no papel de poder de compra temporário que a moeda possui. Nas análises dos neoclássicos, a moeda continua sendo um véu, cuja principal função é a de facilitadora das trocas. Não está em discussão neste ponto a questão da demanda especulativa por moeda proposta por Keynes.

Pelo fato de a moeda representar o poder de compra geral, qual a quantidade de moeda que os agentes econômicos querem manter em média? Isto depende do montante de renda de cada agente econômico. Assim, a quantidade de moeda retida (para a economia como um todo) pelos agentes econômicos é função da renda. Podese escrever:

$$
\mathrm{M}=\mathrm{kPNy}=\mathrm{kPy}
$$

onde:

$\mathrm{k}=$ razão da oferta monetária em relação à renda nominal $(\mathrm{k}=$ $1 / \mathrm{V} ; 0<\mathrm{k} \leq 1)$.

O parâmetro " $k$ " é conhecido como constante marshalliana, e seu valor numérico é igual ao inverso de " $V$ ". Observe-se que ( 5 ) é derivado de ( 4 ). Estabelecendo a condição de equilíbrio, na qual a quantidade demandada deva igualar-se à quantidade ofertada, ao mercado monetário, isto é, à equação ( 6 ), tem-se:

$\mathrm{M}=\mathrm{M}$ ofertada $=\mathrm{M}$ demandada.

De ( 6 ) em ( 5 ):

$\mathrm{M}$ demandada $=\mathrm{kPy}=\mathrm{kNPy}$ 
Logo, a versão de Cambridge expressa a demanda por moeda como uma proporção " $k$ " da renda nominal ("Py' "'). Fica evidente que a relação de causalidade entre oferta monetária e preços depende da estabilidade da velocidade renda da moeda, e, por conseguinte, de " $\mathrm{k}$ ".

A demanda por moeda, implícita, na abordagem dos saldos de caixa, é mais complexa que a demanda marshalliana por um bem ou serviço qualquer que não a por moeda. A equação ( 7 ) pode ser relacionada com a função demanda por moeda, onde:

$\mathrm{M}$ demandada $=f(\mathrm{P}, \mathrm{N}, \mathrm{y}, \mathrm{k})$

Os economistas neoclássicos corroboram a conclusão dos clássicos de que, no longo prazo, há uma proporcionalidade entre expansão na oferta monetária e expansão no nível de preços. Partindo da equação de saldos de caixa de Cambridge, onde $\mathrm{M}=\mathrm{kPy}$ ', com " $k$ " e " $y$ " " constantes, tem-se uma relação proporcional constante a longo prazo entre nível de preços e estoque monetário. A prova disto é trivial. Como " $k$ "e " $y$ " " são constantes no longo prazo, podese reescrever a equação de Cambridge da seguinte forma: $M=k P y$ ' ; logo, se $\mathrm{P}=\mathrm{M}$ ( $1 / \mathrm{y}$ 'k), fazendo $\mathrm{c}=1 / \mathrm{y}$ 'k, onde " $\mathrm{c}$ " é uma constante, temos que $\mathrm{P}=\mathrm{cM}$. Observe-se que se tem uma relação proporcional constante entre o nível de preços, "P", e a oferta monetária, " $\mathrm{M}$ ", no longo prazo. A implicação em termos de política econômica da formulação neoclássica é clara: a política monetária exerce uma poderosa e prevista influência sobre os preços.

No entanto, no curto prazo, os economistas neoclássicos enfatizam a não-neutralidade dos efeitos de uma expansão da oferta monetária. Acreditam que no curto prazo é possível haver um aumento no produto real em decorrência da expansão monetária. Mas, a longo prazo, concordam com os clássicos que afirmam que todo aumento na oferta monetária acima do crescimento do produto real se refletirá em aumento do nível de preços.

Os neoclássicos integraram as conclusões acerca da Teoria Quantitativa da Moeda, na versão dos saldos de caixa, em suas análises dos ciclos de negócios, mostrando como variações na oferta monetária são as causas dos booms e das recessões. Enfatizam que a regulação do nível geral de preços, via política monetária, é um prérequisito para a estabilizaçăo da atividade econômica.

Por fim, cabe ressaltar outra importante contribuição neoclássica: a formalização, elaboração e extensão das idéias sobre controlabilidade da oferta monetária. Fisher, Pigou e outros 
neoclássicos demonstraram que o controle monetário poderia ser executado a partir de uma reserva fracionária do sistema bancário via controle de um exogenamente determinado estoque da base monetária (high-powered money), "B" (Humphrey, 1992, p. 54). Argumentaram que o estoque monetário e os depósitos bancários seriam um múltiplo constante da base monetária (Phillips 1926). Como afirma Foley, "Fisher posits the existence of a given amount of money, exogenously determined in the system" (Foley (1990, p. 256).

Com base neste argumento da controlabilidade da oferta monetária, os monetaristas desenvolveram o conceito de multiplicador monetário, "a" (Friedman 1956). O mesmo é obtido a partir da seguinte igualdade:

$$
\begin{aligned}
& \mathrm{M}=a ́ \mathrm{~B} \\
& (\mathrm{M} / \mathrm{B})=a ́ \\
& \underline{\mathrm{PMPP}}+\mathrm{DV}=a^{\prime} \\
& \mathrm{PMPP}+\mathrm{RB} \\
& \frac{\mathrm{PMPP} / \mathrm{DV}+\frac{1}{\mathrm{PMPP} / \mathrm{DV}+\mathrm{RB} / \mathrm{DV}}}{\mathrm{P}}=a^{2}
\end{aligned}
$$

onde:

$\mathrm{M}$ = oferta monetária;

$\mathrm{B} \quad=$ base monetária;

PMPP = papel moeda em poder do público;

DV = depósitos à vista nos bancos comerciais;

$\mathrm{RB}=$ reservas dos bancos comerciais.

Observe-se que a oferta monetária é função da base monetária, "B", como também dos determinantes, "PMPP/DV" e "RB/DV", do multiplicador monetário, "á ". Os monetaristas, ao suporem o multiplicador monetário como um parâmetro constante, acreditam que as autoridades monetárias podem determinar o nível da oferta monetária via controle efetivo da base monetária. Tanto é assim, que: "For secular movements, Cagan finds that high-powered money is the major source of changes in the stock of money. During most of the period studied, increases in prices would be expected to have reduced the quantity of high-powered money by discouraging gold output and encouraging gold exports" (Friedman 1964, p. 8).

Desta forma, pode-se afirmar que a Teoria Quantitativa da Moeda consiste em um conjunto de proposiçōes inter-relacionadas, ou postulados, que embasam a conclusão principal, de que:

$P=f(M)$. Tais postulados são: 
i) PROPORCIONALIDADE: Estabelece que "P" variará exatamente na mesma proporção que variar " $M$ ". Esta hipótese implica que os saldos reais demandados pelos agentes, (M / P), bem como "V" são estáveis. Se (M/P) ou "V" forem instáveis, não se pode dizer que " $M$ " e " $P$ " variem na mesma proporção. Portanto, disto segue que a Teoria Quantitativa da Moeda assume estabilidade completa na demanda por saldos reais, $M / P$, se for para prognosticar que a oferta monetária e o nível geral de preços variarão nas mesmas proporções.

ii) CAUSALIDADE: Variaçōes na oferta monetária precedem e causam variações no nível de preços. A moeda é considerada a variável ativa enquanto o nível de preços é considerado a variável passiva. Os economistas clássicos advogam que o processo de ajustamento se dá de forma instantânea, enquanto os neoclássicos acreditam que, embora haja uma relação de causalidade entre " $P$ " e " $M$ ", $\mathrm{P}=f(\mathrm{M})$, a proporcionalidade refere-se a uma condição de equilíbrio estabelecido via um processo de ajustamento dinâmico, e não a uma identidade que se verifica em todos os pontos do tempo. $\mathrm{O}$ processo de ajuste é defasado. Inicialmente, uma mudança na oferta monetária cria um desequilíbrio nos saldos demandados, $\mathrm{M} / \mathrm{P}$. Este desequilíbrio invoca forças que causam variações no nível de preços. O processo de ajuste se dá por dois canais:

1) direto: $O$ impacto da variação monetária é canalizado para o nível de preços via demanda por bens e serviços. Se há um aumento na oferta monetária, então os saldos reais possuídos pelos agentes são maiores que os saldos reais desejados. Dessa forma, os agentes gastarão o excesso de moeda adquirindo bens e serviços. Como a economia encontra- se a pleno emprego dos fatores de produção, o excesso de gasto implica aumento do nível de preços. Assim, gastos, nivel de preços e renda nominal continuarão crescendo até que o saldo real efetivo seja igual ao saldo real desejado.

2) indireto: Aqui, gastos e nível de preços são afetados pela variação monetária indiretamente, via seu efeito antecedente sobre a taxa de juros. Uma expansão na oferta monetária implica uma queda na taxa de juros. Se a taxa de juros cair a um patamar que esteja abaixo da taxa de lucro médio sobre o investimento em capital fixo, então haverá um estímulo ao aumento da taxa de investimento agregado na economia. Este aumento na taxa de investimento agregado na economia implicará aumento no nível geral de preços, pois a economia encontra-se em pleno emprego. 
iii) NEUTRALIDADE: Exceto para períodos transitórios de ajustamento (ponto destacado pelos neoclássicos), variáveis monetárias não afetam variáveis reais. No longo prazo a moeda é um véu que não afeta a operação das forças econômicas reais. Observe que no curto prazo variáveis monetárias podem afetar variáveis reais. Mas, tal efeito só se verifica no período transitório de ajuste. No longo prazo a dicotomia clássica se faz presente.

iv) TEORIA MONETÁRIA DO NÍVEL DE PREÇOS: Estabelece que o nível de preços tende a ser influenciado predominantemente pela oferta monetária. Assim, a instabilidade no nível de preços deriva-se, principalmente, dos distúrbios monetários em vez dos nãomonetários. Logo, a inflação/deflação surge do comportamento errático da oferta monetária ao invés de causas não-monetárias originadas no setor real da economia. Observe-se que a hipótese (iv) é muito importante para a construção do ferramental analítico da Teoria Quantitativa da Moeda. A hipótese (iv ) surge porque a hipótese ( iii ) é uma condição necessária mas não suficiente para a determinação do nível de preços. A hipótese ( iii ) não afirma que somente variáveis monetárias afetem o nível de preços, abrindo espaço para que variáveis não-monetárias afetem o nível de preços. Com a inclusão da hipótese ( iv ), o nível de preços variará, se e só se houver uma variação na oferta monetária. É importante ter em mente que a hipótese (iv ) se refere única e exclusivamente ao nível geral de preços, e não aos movimentos de preços relativos. Os monetaristas aceitam que variáveis reais, como quebra de safra e progresso tecnológico, afetem os preços relativos. Mas sustentam que este é um jogo de soma zero, que pode alterar os preços relativos na economia mas mantém o nível geral de preços constante. Esta hipótese permite aos monetaristas concluírem que são os choques monetários e não os distúrbios no setor real da economia que exercem o efeito dominante sobre o nível geral de preços.

v) EXOGENIDADE DO ESTOQUE NOMINAL DE MOEDA: Este é o corolário que sustenta a conclusão monetarista de que $\mathrm{P}=f(\mathrm{M})$. Se a quantidade ofertada de moeda não for independente da quantidade demandada, então não se poderia alegar que a oferta monetária tem papel ativo na determinação do nível de preços. A visão de que as autoridades monetárias controlam a oferta monetária advém da suposição de que o multiplicador monetário, “á”, é constante $(M=a ́ B)$. Como as autoridades monetárias controlam a base monetária, "B", e o multiplicador monetário, "á", é constante, então 
a oferta monetária é determinada exogenamente pelas autoridades monetárias. Observe-se que a hipótese $(\mathrm{v})$ diz respeito à exogenidade do estoque nominal de moeda, e não do estoque real de moeda. $\mathrm{O}$ estoque real de moeda é endógeno e determinado pela demanda do público por saldos reais. Alguns simpatizantes do ideário monetarista tentam suavizar esta hipótese, afirmando que exogenidade e controlabilidade da oferta monetária são conceitos distintos. Para estes analistas, as autoridades monetárias têm, sim, o controle da oferta monetária, mas argumentam que nos modelos monetaristas a moeda pode ser uma variável endógena ${ }^{6}$.

A pergunta que fica após esta longa explanação é: como os monetaristas definem moeda para fins de política monetária? Segundo os mesmos, isto depende de dois fatores. Primeiro, depende da habilidade das autoridades monetárias em controlar sua quantidade, e, em segundo lugar, depende da estabilidade empírica da função demanda por moeda. Friedman $\mathcal{E} \mathrm{Schwartz,}$ em seu clássico estudo A Monetary History of the United States, 1867-1960, utilizam a definição de M2 como a melhor proxy para a moeda. Na definição do FED, M2 é igual a M1 acrescentado dos depósitos em caderneta de poupança.

Os monetaristas supõem que a quase-moeda? tem ligaçōes estáveis com a moeda. A Teoria Quantitativa da Moeda nunca negou que a quase-moeda possa influenciar gastos e preços como a moeda o faz. Mas a Teoria Quantitativa da Moeda nega que o volume de quase-moeda possa expandir-se ou contrair-se independentemente do volume de moeda e então atuar como uma influência autônoma sobre o nível de preços.

\footnotetext{
6 "A segunda hipótese da visão monetarista do processo inflacionário afirma que o estoque de moeda é controlável pelas autoridades monetárias. Esta proposição não significa dizer que o controle seja efetivamente exercido, ou que a quantidade de moeda seja uma variável exógena no modelo monetarista. O sentido da hipótese é de que as autoridades monetárias dispõem de instrumentos capazes de afetar com precisão, obviamente não no dia-a-dia, o volume de moeda. É importante assinalar que inexiste qualquer empecilho para que a oferta de moeda seja uma variável endógena em um modelo monetarista. Nem sempre é bem compreendido por analistas do processo inflacionário brasileiro o fato de que endogenidade e controlabilidade não significam a mesma coisa" (Barbosa, 1983, p. 70).

$7 \mathrm{O}$ conceito de quase-moeda corresponde aos depósitos bancários a prazo e aos títulos, públicos e privados, de curto prazo que podem ser rapidamente convertidos em moeda sem perda significativa de valor para seus possuidores.

$7 \mathrm{O}$ conceito de quase-moeda corresponde aos depósitos bancários a prazo e aos títulos, públicos e privados, de curto prazo que podem ser rapidamente convertidos em moeda sem perda significativa de valor para seus possuidores.
} 


\section{A Nova Apresentação da Teoria Quantitativa da Moeda por Friedman}

A re-interpretação que Friedman faz da Teoria Quantitativa da Moeda consiste, basicamente, em extrair desta uma teoria da demanda por moeda, mais do que uma teoria da determinação do nível de preços e da renda nominal.

Na visão de Friedman, a Teoria Quantitativa da Moeda estabelece que:

1) é a quantidade real de moeda $(M / P)$, mais do que a quantidade nominal de moeda, ( $M$ ), que realmente importa para os agentes econômicos.

2) em qualquer situação, os agentes querem reter uma bem-definida quantidade real de moeda.

As pessoas tendem a ser extraordinariamente obstinadas a respeito da quantidade real de dinheiro que desejam ter em seu poder e pouco dispostas a aceitar uma quantidade diferente, a menos que tenham real incentivo para fazê-lo. Isso é verdade não só no tempo quanto no espaço.(...) Mas, ainda que consideremos os números como se apresentam, são reveladores de marcante uniformidade. Temos aí países com todas as formas de sistema econômico, com rendas reais que variam numa proporção de 15 ou 20 para 1, e, contudo, os saldos monetários retidos pela população, expressos em termos de semanas de renda, variam numa proporção de menos de 2 para 1 (Friedman, 1969, p. 36).

Como pode-se observar a partir das citaçōes acima, Friedman chega à mesma conclusão de seus colegas neoclássicos: a de que mudanças substanciais no nível de preços e na renda nominal são quase sempre resultado de mudanças na oferta monetária nominal.

$\mathrm{O}$ argumento de Friedman é similar ao dos clássicos. Parte-se de uma situação de equilíbrio, no qual os saldos nominais mantidos pelos agentes são iguais aos saldos reais desejados. Assim, uma expansão da oferta monetária implica aumento do gasto agregado, pois os agentes gastam para se desfazerem do excesso de moeda, e, desta forma, retomarem o equilíbrio de seus saldos reais. Isto pode funcionar para um agente individual mas não funciona para a economia como um todo, pois o gasto de um agente é a receita de outro. Um agente só pode diminuir seu saldo monetário nominal se persuadir algum outro a aumentar seu saldo monetário nominal ${ }^{8}$. Logo, a

8 “Não é difícil encontrar razōes para a grande popularidade dessas teorias. São duas, creio eu. A primeira é a tendência natural de confundir o que é verdadeiro para o indivíduo com que o 
comunidade como um todo não pode gastar mais que suas receitas. Conseqüentemente, uma expansão na oferta monetária só afeta o nível de preços.

Friedman segue sua análise ressaltando que as muitas versōes da Teoria Quantitativa da Moeda tem-se preocupado em termos dos níveis das variáveis envolvidas. Para a análise das alteraçōes na oferta monetária é mais útil expressar tais mudanças em termos das taxas de variação. Assim, sabe-se que: $\mathrm{MV}=\mathrm{PT}$

onde, $\mathrm{T}=\mathrm{Ny}=\mathrm{y}^{\prime}$, logo

$$
\begin{aligned}
& M V=P y^{\prime} \\
& \ln (M V)=\ln \left(P^{\prime}\right) \\
& \ln (M)+\ln (V)=\ln (P)+\ln \left(y^{\prime}\right)
\end{aligned}
$$

Diferenciando ambos os lados da equação acima em relação ao tempo, tem-se:

$\frac{1}{M} \frac{\ddot{a} M}{\ddot{a} t}+\frac{1}{V} \frac{\ddot{a} V}{\text { ät }}=\frac{1}{P} \frac{a p}{a ̈ t}+\frac{1}{y^{\prime}} \frac{\ddot{a d y}}{a ̈ t}$

Reescrevendo ( 8 ) tem-se:

$\mathrm{Gm}+\mathrm{Gv}=\mathrm{Gp}+\mathrm{Gy}$

onde " $G$ " é a taxa de mudança percentual.

Uma mudança na taxa de crescimento da oferta monetária, "Gm", de acordo com ( 8 ) e ( 9 ) tende a ser acompanhada por uma mudança na taxa de inflação, "Gp", sendo que um aumento na taxa de inflação aumenta o custo de oportunidade de reter moeda, e, por conseguinte, diminui a demanda por saldos monetários reais.

Observe que uma mudança na demanda por saldos monetários reais afeta variáveis reais como " $\mathrm{V}$ " $\mathrm{e}$ " $\mathrm{y}$ ", , bem como a taxa de juros nominal e real.

Os fatores determinantes da oferta monetária dependem, basicamente, do sistema monetário, a saber: a base monetária, e os valores de "DV / RB" e "DV / PMPP" (que determinam o valor do multiplicador monetário). Friedman destaca que a quantidade nominal de moeda é determinada, primariamente, pela oferta e que a quantidade real de moeda é determinada, primariamente, pela demanda. Segundo Friedman, a oferta monetária, "Ms", é função de variáveis como taxa de inflação ( $\mathrm{p}$ ), renda nominal ( $\mathrm{Y}$ ), taxa de

que é verdadeiro para a sociedade, como um todo. $O$ fato mais importante e interessante a respeito das ciências econômicas é, exatamente, que quase toda regra que se aplica aos indivíduos não é válida para a sociedade e quase tươ que é válido para a sociedade não o é para o indivíduo" (Friedman, 1969, p. 28), 
juros ( $R$, onde $R$ é um vetor das taxas de juros) e outras. Pode-se escrever a oferta monetária como:

$\mathrm{Ms}=f(\mathrm{R} ;$ ð; $\mathrm{Y} ; . .$.

Ao expor a sua teoria da demanda por moeda, Friedman destaca que a versão dos saldos de caixa de Cambridge, da Teoria Quantitativa da Moeda, ressalta o papel da moeda como um ativo, sugerindo tratar a demanda por moeda como parte do capital ou da teoria da riqueza (destacando a composição do portfólio de ativos dos agentes).

Para os consumidores, a moeda é a manifestação última de sua riqueza, e, para as firmas, a moeda é um insumo como outro qualquer utilizado no seu processo de produção. Para os detentores de riqueza final, a demanda por saldos reais é função de algumas variáveis como:

- Riqueza Total: tem o mesmo papel da restrição orçamentária na teoria da escolha do consumidor. A riqueza total do agente pode ser alocada em diversas formas de ativos, monetários ou não. Friedman argumenta que o conceito de renda permanente pode ser uma boa aproximação da riqueza total do agente.

- Divisão da Riqueza na Forma Humana e Não Humana: o maior ativo que muitos agentes possuem é sua capacidade de aprendizado. Os agentes podem usar o seu conhecimento pessoal para adquirir riqueza não-humana, mas esta conversão é sujeita a estreitos limites devido a restrições institucionais. Da mesma forma, os agentes podem utilizar riqueza não-humana para financiarem a aquisição de conhecimento. Devido a estes entraves institucionais, a riqueza humana é muito mais ilíquida do que a riqueza não-humana. Assim, determinado o estoque de riqueza do indivíduo, quanto maior for a participação da riqueza humana no portfólio do agente, maior será a demanda por moeda deste agente de modo a compensar a iliquidez da riqueza humana.

- Taxa Esperada de Retorno da Moeda e outros Ativos: a taxa nominal de retorno da moeda é normalmente igual a zero. Aqui não está sendo levado em consideraçāo o caso de taxas de retorno positivas (caso das contas-correntes remuneradas) ou negativas (caso de pagamento de serviços bancários). Já a taxa nominal de retorno dos outros ativos depende:

1. Das taxas de juros que estes ativos pagam;

2. Da mudança do preço destes ativos, de especial importância em períodos de inflação e/ou deflação. 
- Preferência pela Liquidez: neste ponto, Friedman utiliza a terminologia mas não o conceito keynesiano. Para Friedman, os agentes têm certa "necessidade" de reter moeda, pois, conforme sua renda corrente aumenta, o seu consumo também aumenta, mas não na mesma proporçāo do aumento em sua renda corrente. Logo, os agentes mantêm este excesso de renda não gasta na forma de moeda.

- Grau de Estabilidade Econômica Esperada a Ocorrer: ambientes onde prevalece a instabilidade aumentam a importância do motivo preferência pela liquidez (novamente, se está tratando aqui da nomenclatura de Friedman e não de Lord Keynes). Estes ambientes de instabilidade são difíceis de serem observados quantitativamente, embora qualitativamente seja possível prever suas direções, via aumento ou diminuição da preferência pela liquidez. Um exemplo de ambiente de instabilidade é o ato de declaração de guerra. A eminência de um conflito armado entre países normalmente faz com que haja um aumento na demanda por saldos reais dos agentes residentes nestes países, e, a conseqüente diminuição da velocidade de circulação da moeda que acompanha tais eventos.

- Taxa de Inflação: o aumento na taxa de inflação, p, aumenta o custo de oportunidade de reter moeda e é o principal elemento que afeta a utilidade de sua retenção.

Assim, pode-se representar a demanda por saldos reais, Md, de um agente representativo como sendo função de variáveis como nível geral de preços $(\mathrm{P})$; oferta monetária $(\mathrm{M})$; renda nacional a preços constantes $\left(\mathrm{y}^{\prime}\right)$; taxa de retorno nominal esperada da moeda $\left(\mathrm{R}^{*}\right)$; taxa de retorno nominal esperada dos títulos $\left(\mathrm{R}^{* *}\right)$; taxa de retorno nominal esperada dos ativos fixos $\left(\mathrm{R}^{* * *}\right)$; fração da riqueza do agente em forma humana em relação à forma não-humana (w); outras variáveis que afetam a utilidade de reter moeda $(\mu)$. Assim, tem-se:

$$
\mathrm{Md}=\mathrm{P} \quad f\left(\mathrm{y}^{\prime} ; \mathrm{w} ; \mathrm{R}^{*} ; \mathrm{R}^{* *} ; \mathrm{R}^{* * *} ; \mu\right)
$$

Tanto " $R^{* *}$ " quanto " $R^{* * *}$ incluem as expectativas de mudança nos preços dos títulos e dos ativos fixos. Embora a taxa de inflação não esteja explícita em ( 11 ), a mesma está implícita na referida equação porque afeta o retorno nominal esperado de várias classes de ativos e às vezes é usado como uma proxy para " $\mathrm{R} * * *$ ". É importante observar que a equação acima de demanda por moeda de um agente representativo independe da unidade monetária utilizada para medir as variáveis monetárias. Logo, se a unidade monetária na 
qual são expressos os preços e a renda monetária for alterada, a quantidade de moeda demandada será alterada na mesma proporção.

No processo de agregação da equação ( 11 ) de um agente representativo para a equação de demanda por saldos reais da economia como um todo, é preciso ter certos cuidados. Caso se faça este processo de agregação mecanicamente, se está supondo que tanto " $y$ " ( $y^{\prime}=N y$, logo $y=y$ '/ N ) quanto " $w$ " estão distribuídos uniformemente entre todos os agentes. Um modo de suavizar esta hipótese é agregar "y" e "w" pelos seus valores médios. Aplicandose estes valores médios na equação ( 11 ), tem-se "y" como a renda per capita real e "w" como o valor social médio da fração da riqueza agregada na forma humana em relação à forma não-humana.

O tratamento da demanda por saldos reais das empresas difere um pouco do método utilizado para obter-se a demanda por saldos reais dos detentores de riqueza última, os consumidores. As empresas não estão sujeitas, como os consumidores estão, às restrições impostas pela riqueza total. Elas podem determinar o montante de capital incorporado em ativos produtivos, incluindo moeda, para maximizarem seus lucros, desde que tenham acesso a capital adicional nos mercados de capitais. Alguns indicadores que podem ser utilizados para obter-se a demanda por moeda das empresas são: transações totais efetuadas pelas empresas; valor adicionado líquido gerado; receitas líquidas; capital total na forma não-monetária; taxas de retorno da moeda e de outros ativos monetários (estas taxas determinam o custo de reter saldos monetários). Para as empresas, a taxa mais importante é a taxa de custo de captação de empréstimos nos mercados financeiros. Assim, pode-se representar a demanda por moeda das empresas como sendo:

$$
\mathrm{Md}=\mathrm{P} \quad f\left(\mathrm{y} ; \mathrm{R}^{*} ; \mathrm{R}^{* *} ; \mathrm{R}^{* * *} ; \mu\right)
$$

No caso das empresas, a variável " $\mathrm{W}$ “ pode ser desprezada.

Para Friedman, um dos pontos fundamentais da Teoria Quantitativa da Moeda é ressaltar que o nível de preços e o nível de renda nominal são resultantes da interação entre oferta e demanda por moeda.

Multiplicando a equação ( 11 ) por " $N$ ", para converter-se a demanda por moeda da forma per capita para a forma agregada, e igualando oferta e demanda por moeda para obter-se a condição de equilíbrio no mercado monetário, tem-se:

$$
\mathrm{Ms}=\mathrm{Ms}(\mathrm{R} ; \mathrm{Y} ; \mathrm{p} ; \ldots)=\mathrm{PN} f(\mathrm{y} ; \mathrm{R} ; \mathrm{w} ; \mathrm{Gp} ; \mu)
$$


Na equação acima, " $R$ " corresponde a um vetor de taxas esperadas de juros.

Observe-se que a equação acima nada mais é do que a equação de saldos de caixa de Cambridge expandida. Friedman chega basicamente à mesma conclusão dos neoclássicos de Cambridge: que a demanda por moeda, saldos reais na terminologia friedmaniana, é uma função estável do nível de renda real'. O que Friedman faz é uma análise mais elegante da demanda por saldos reais, ao acrescentar algumas variáveis que os neoclássicos não utilizavam, e acrescentar a renda permanente como uma boa aproximação da riqueza do agente, no caso da demanda por saldos reais de um agente individual. Como já foi mencionado anteriormente, os monetaristas concordam com os economistas neoclássicos que o processo de ajustamento temporal da economia a uma expansão da oferta monetária é dinâmico, e não estático (como propõem os clássicos). Ainda que no curto prazo o aumento da oferta monetária possa aumentar o produto agregado real, no longo prazo este aumento se refletirá em igual aumento no nível geral de preços.

\section{Princípios de Política Econômica Propostos pelos Monetaristas a Partir da Reinterpretação da Teoria Quanti- tativa da Moeda}

Mesmo que os monetaristas discordem dos economistas clássicos no que tange ao axioma da proporcionalidade, ambas as escolas advogam o mesmo princípio de política monetária. A de que a expansão na oferta monetária deva ser igual à taxa de crescimento do produto real, para evitar aumento no nível geral de preços. A discordância sobre o axioma da proporcionalidade surge, pois a Escola Clássica supõe existir uma estabilidade perfeita da demanda por saldos reais, isto é, qualquer expansão na oferta monetária é imediatamente repassada para o nível geral de preços. Já a Escola Monetarista aceita o fato de que a demanda por saldos reais não seja perfeitamente estável no curto prazo - ainda que sua variância seja muito pequena, e, em conseqüencia disto, o processo de ajustamento temporal não seja imediato, e sim dinâmico.

${ }^{9}$ Entende-se, neste caso, que a função demanda por moeda seja estável. 
Em última instância, as conclusões monetaristas são um contraponto à teoria keynesiana, ao negar a tese de que a política fiscal seja a mais eficiente ferramenta de estabilização da demanda agregada, e ao defender, a utilização da política monetária como instrumento mais apropriado para este fim. Além disto, para os monetaristas, a política monetária possui um poderoso impacto de longo prazo sobre a renda nominal, ao ser o determinante do nível de preços.

Em A Program for Monetary Stability (1960), Friedman propõe que as autoridades monetárias adotem uma política de crescimento constante da oferta monetária como forma mais simples e eficiente para estabilizar a economia. Na ótica monetarista, as autoridades monetárias devem utilizar as médias históricas das taxas de crescimento do produto real como guia para aumentos na oferta monetária.

Este receituário proposto por Friedman advém da crença dos monetaristas de que a política monetária tem um lag de seis meses a dois anos para surtir efeito. Assim, a adoção de uma política monetária contra-cíclica pelas autoridades monetárias pode acabar exacerbando as flutuações econômicas ao invés de estabilizar a atividade econômica. Deste modo, na ótica monetarista, as autoridades monetárias, ao adotarem uma política de crescimento constante da oferta monetária, eliminam as fontes de distúrbios econômicos e aproximam-se de um nível de preços constante ao longo do tempo. Ao agirem desta forma, as autoridades monetárias removem as incertezas dos investidores advindas de efeitos inesperados de uma política monetária discricionária.

A receita monetarista é simples: a adoção de uma regra clara e objetiva de política monetária é mais eficiente do que o uso de práticas discricionárias por parte das autoridades monetárias.

Tal rigidez teórica desta escola de pensamento advém da negação, por parte dos monetaristas, de algumas ferramentas macroeconômicas desenvolvidas a partir da década de 1950 .

Os monetaristas negam existir um trade-off entre inflação e nível de emprego, como afirma a primeira versão da curva de Phillips com expectativas estáticas. Alegam que este trade-off depende do grau de rigidez salarial existente na economia. Mas, no longo prazo, dizem os monetaristas, a curva de Phillips é vertical - não existindo qualquer possibilidade de troca entre taxa de inflação e aumento nos níveis de emprego. Para comprovar sua tese estes economistas citam o caso dos Estados Unidos na década de 1970, quando altas 
taxas de inflação e em constante crescimento conviviam com baixos niveis de emprego.

Friedman argumenta que a economia gravita em torno de sua "taxa natural de desemprego", a qual, no longo prazo, é independente da taxa de inflação, portanto não podendo ser afetada pela política monetária. Ainda, segundo os monetaristas, qualquer tentativa de manter a taxa de desemprego abaixo de sua taxa natural só será eficiente se as autoridades monetárias conseguirem surpreender os agentes, fazendo com que a taxa efetiva de inflação seja maior que a taxa esperada de inflação. Mas, para que a taxa de desemprego se mantenha abaixo de sua taxa natural indefinidamente, é necessário que a inflação se acelere, para que as expectativas inflacionárias dos agentes sejam constantemente frustradas. Este "princípio da aceleração", ou curva de Phillips aceleracionista na terminologia macroeconômica, comprova que não existe um trade-off estável entre inflação e nível de emprego, fazendo com que, no longo prazo, a curva de Phillips seja vertical, isto é, uma política monetária expansiva somente aumenta o nível de preços sem afetar o nível de emprego.

A existência da "taxa natural de desemprego" implica que a estabilidade de preços não guia a economia a operar com uma alta taxa de desemprego no longo prazo. Caso o governo não imponha uma legislação trabalhista que impeça o funcionamento dos mecanismos de mercado, no longo prazo não existirá desemprego estrutural - somente o desemprego friccional (ou a "taxa natural de desemprego" na terminologia monetarista).

Outro fator a ser destacado na análise monetarista é a de que as autoridades monetárias devem enfatizar o controle da oferta monetária em detrimento da taxa de juros. Muitos bancos centrais tentam controlar as taxas de juros, e, ao agirem desta forma, acabam intervindo nas condições de crédito da economia. Na visão de Friedman, o preço do dinheiro é a quantidade de bens e serviços que uma unidade monetária pode adquirir. Logo, o preço do dinheiro varia inversamente com o nível de preços. Já o preço do crédito é a taxa de juros. A taxa de juros relaciona estoques a fluxos. O valor do serviço de uma unidade monetária, variável de fluxo, em relação ao preço do dinheiro, variável de estoque. Assim, tanto as pessoas como os police makers tendem a confundir moeda com crédito.

Em A Monetary History of the United States, 1860-1960, Friedman $\mathcal{E}$ Schwartz afirmam a importância que a oferta monetária possui 
para afetar os ciclos econômicos. Os autores argumentam que a espetacular contração da atividade econômica, observada no período de 1929 a 1933, foi causada por uma incomum contração da oferta monetária. O FED, ao permitir que a oferta monetária se contraísse em aproximadamente 33\% (ao preocupar-se em monitorar as condiçōes de crédito - taxas de juros - da economia norte-americana em detrimento do controle da oferta monetária), foi o principal responsável, na ótica monetarista, pela grande depressão.

É importante ressaltar que os monetaristas foram os primeiros críticos da teoria keynesiana da armadilha da liquidez. Negam a hipótese de que haja uma alta elasticidade da demanda por moeda em relação às alteraçōes de curto prazo nas taxas de juros de outros ativos líquidos. Estudos empíricos revelaram que no caso da economia norte-americana a elasticidade da demanda por moeda em relação à taxa de juros é próxima de zero, fato este que corrobora a tese monetarista de que a demanda por saldos reais depende basicamente da riqueza total dos agentes.

Assim, a política monetária ótima é aquela que garanta uma taxa de inflação muito próxima de zero, para que as taxas de juros real e nominal tendam a convergir para um valor comum.

Enfim, sāo estas premissas e conclusões do corpo teórico monetarista que levaram Friedman a concluir que "...inflation is always and everywhere a monetary phenomenon - in the sense that it is and can be produced only by a more rapid increase in the quantity of money than in output" (Friedman, 1970, p. 25).

\section{Conclusão}

A principal conclusão deste artigo é a de que a Teoria Quantitativa da Moeda foi reinterpretada por Friedman como uma teoria da demanda por moeda, mais do que uma teoria da determinação do nível de preços e da renda nominal.

Friedman, ao observar que no longo prazo a inflação era causada por um grande crescimento da oferta monetária em relação ao produto real agregado, estabeleceu que a inflação é sempre e em todo lugar um fenômeno monetário. Tanto que, constantemente, cita em seus papers os casos das hiperinflações européias (Alemanha e Áustria no pós-Primeira Guerra e Hungria e Grécia no pós-Segunda Guerra), como exemplos de que foram os excessivos aumentos 
na oferta monetária que causaram os crônicos processos inflacionários nestes países.

Os monetaristas fixam sua análise no longo prazo. Aceitam que uma expansão da oferta monetária pode, no curto prazo, ter algum efeito sobre o produto agregado real, mas enfatizam que, no longo prazo, tal política somente terá impacto sobre o nível geral de preços. Além disto, rejeitam as políticas econômicas que no longo prazo visam aumentar os níveis de emprego, e, por conseguinte, de renda real agregada via expansão da oferta monetária. Na ótica monetarista, este comportamento de curto prazo da política monetária pode ser conflitante com objetivos de longo prazo, como estabilização do nível geral de preços e a obtenção do máximo crescimento econômico, objetivo este que está além do alcance da política monetária.

Para encerrar, lembra-se as palavras de Cagan (1990, p. 203) que resumem bem o tema deste artigo: "Monetarists believe that economic activity, apart from monetary disturbances, is inherently stable. Much of their disagreement with Keynesians can be traced to this issue" (Friedman, 1970, p. 25).

\section{Referências bibliográficas}

ACKLEY, G (1978) Teoria Macroeconômica, Volume 1, São Paulo, Ed. Pioneira.

ANGEL, J. W. (1936) The Behavior of Money. New York, McGraw-Hill.

BARBOSA, Fernando. H (1983) A Inflação Brasileira no Pós-Guerra: Monetarismo versus Estruturalismo. Rio de Janeiro, IPEA/INPES

BRUNNER, Karl (1990) High-Powered Money and the Monetary Base. In: Eatwell et all. (1990) The New Palgrave: Money. London, The MacMillan Press.

BRUNNER, Karl (1990) Money Supply. In: Eatwell et al. (1990) The New Palgrave: Money. London, The MacMillan Press.

CAGAN, Philip (1990) Hyperinflation. In: Eatwell et al. (1990) The New Palgrave: Money. London, The MacMillan Press.

CAGAN, Philip (1990) Monetarism. In: Eatwell et al. (1990) The New Palgrave: Money. London, The MacMillan Press.

CORAZZA, Gentil (1996) O Monetarismo ou a Negaçāo da Moeda. Maringá, Economia em revista, Vol. V, número 1.

CRAMER, J. S. (1990) Velocity of circulation. In: Eatwell et al. (1990) The New Palgrave: Money. London, The MacMillan Press. 
FOLEY, D (1990) Money in Economic Activity. In: Eatwell et al. (1990) The New Palgrave: Money. London, The MacMillan Press.

FRIEDMAN, Milton (1956) Studies in the Quantity Theory of Money. Chicago. The University of Chicago Press.

FRIEDMAN, Milton (1964) The Monetary Studies of The National Bureau. In: Gibson, W. E. E Kaufman, G. C. (1971) Monetary Economics: Readings on Current Issues. New York, McGraw-Hill.

FRIEDMAN, Milton (1969) Inflação: Suas Causas e Conseqüências. Rio de Janeiro. Ed. Expressão e Cultura.

FRIEDMAN, Milton (1970) The Counter-Revolution in Monetary Theory. Wincott Memorial Lecture.

FRIEDMAN, Milton (1990) Quantity Theory of Money. In: Eatwell et al. (1990) The New Palgrave: Money. London, The MacMillan Press.

GAREGNANI, P. (1978) "Notes on consumption, investment and effective demand: I", Cambridge Journal of Economics, Vol. 2, no. 4, p. 335-353. December.

HUMPHREY, T. H. (1992) A Teoria Quantitativa da Moeda: evolução histórica e papel nos debates políticos. Campinas, IE-Unicamp, Texto Didático, Teoria Monetária, Introdução e tradução de Fernando Nogueira da Costa.

PATINKIN, D. (1965) Money, Interest and Prices. New York. Harper $\mathcal{B}$ Row.

PHILLIPS, C. A. (1926) Bank Credit. New York. McMillan Press.

SAMUELSON, P. E NORDHAUS, W. (1988) Economia. Lisboa. Ed. McGraw-Hill

SIMONSEN, M.H. (1983) Dinâmica Macroeconômica, São Paulo, McGraw-Hill.

SPIEGEL, Henry W. (1991) The Growth of Economic Thought. Durham. Duke University Press.

SWAELEN, E. J. A. (1982) Desemprego, Salários e Preços: Um estudo comparativo de Keynes e do pensamento macroeconômico da década de 1970. Dissertação de Mestrado. Departamento de Economia da UFRJ. Rio de Janeiro. 